\title{
Some Cosmological Roots of Modern ArChitecture
}

\author{
Rudolf Klein \\ Institute of Architecture, Ybl Miklós Faculty of Architecture and Civil Engineering, \\ Szent István University, Budapest, Hungary \\ kleinrud@gmail.com
}

\begin{abstract}
This paper investigates the links between some oriental cosmologies and modern architecture, stemming from major non-Western religions, such as Buddhism, Islam and Judaism as well as from Einstein's theories. It analyses both the direct impact of these concepts, influencing modernism at a theoretical level, and their indirect impact through historic non-Western architecture, mainly Buddhist and Islamic. While modernist theoreticians and architects frequently emphasised functional and technical priorities of modernism, I argue that modernism was far less rational than it is commonly thought, and that it was substantially influenced by non-Western thought, particularly in its early period.

This paper considers two main innovations of modernism resulting from oriental concepts of void: (1) the flat and undecorated façade, the avoidance of traditional 'façade-discourse', (2) the promotion of space as the main objective of architecture. The impact of Buddhist, Islamic, Judaic and the Einstenian cosmologies on modernism are considered.
\end{abstract}

Keywords: Modernism, Islam, Buddhism, Judaism, Albert Einstein

\section{INTRODUCTION}

Historic evidence proves that architecture's role has often been to cosmicise, i.e. to connect human existence with the universe, including its imagined creator(s) and governor(s). Ancient people first tried to establish links with the heaven(s) in the form of sacred pillars or obelisks, and to secure a habitat for their gods, and only then looked for a permanent shelter for themselves. Spatial arrangements of sacred buildings and human settlements often represented the comprehended universe, in order to secure a link between macrocosm and microcosm. The Ptolemaist cosmos influenced Aristotle's aesthetics and, with that, architectural space, which - as Greek and Roman temples bear witness to - was limited (horismenon). Judeo-Christian comprehension of the universe was primarily temporal, which prompted the longitudinal arrangement of church interiors and an intense involvement of time in the perception of space. Biblical thought was replaced by new ideas about the universe resulted from heliocentric theories of the Renaissance, which later evolved into the modern cosmology based on Einstein's theories in the beginning of the $20^{\text {th }}$ century.

Modern architecture has sometimes been defined as a synthesis of these two concepts, i.e. interplay between the bodily character of ancient architecture and the spaciousness of the sacred architecture of Christianity, as explained by Siegfried Gidion in his seminal work, Space, 
Time, Architecture in 1939. We will see soon that Gidion's view is rather limited, as he confines the ideatic and formal roots of modernism to Western culture. More often, however, twentiethcentury modernism defined itself as rational, functional and technical against the backdrop of an architectural history considered over-decorated and cluttered by tradition, which had lost its meaning, purity and impact over the course of time. In other words, modernists did their best to free mankind from tradition, to 'de-culturate' architecture in their effort to adapt it to the needs of the so-called machine age.

I argue that some modernists were merely paying lip service to these goals and that modernism did not only meet the demands of technology, but it also incorporated historic elements and traditions. These were just different historic elements and traditions from before. In addition to Greco-Roman and Christian civilisation - the basis of western culture - they drew on the heritage of Islamic, Buddhist and Judaic cultures. (Many other non-western influences, such as Mazdaism, which impacted the early Bauhaus via Johannes Itten, and many aspects of anthroposophy and Rudolf Steiner, are not dealt with in this paper.)

Modernism merged the technical achievements of the day with the numerous cultural traditions of different civilisations, heralding an artistic globalisation, much before the actual arrival of economic globalisation. The technical achievements included the introduction of cast iron, steel and reinforced concrete structures, shell and mixed constructions, and later the use of synthetic materials. Culturally modern architecture was impacted by modern art (also partly influenced by non-western sources), western elements of architectural history, conventions concerning structure, modern function, and non-Western cosmologies embedded in religious teachings, including their artistic and architectural products.

In visual terms twentieth-century modern architecture has evolved along two ideological and strategic principles. In the first place, modernism avoided figural discourse, that is to say, communication via conventional anthropomorphic or zoomorphic as well as floral symbols, thus eliminating symbolic writing on the surface of the façades, challenging the idea of any meaning beyond the realm of pure architecture. Secondly, it promoted space as the main constituent and the ultimate goal of architecture. Both principles have deep roots in the cosmologies of non-Western religions, mystical teachings and their interpretation by modern philosophy or science.

\section{HISTORIC PERSPECTIVE}

Western art gradually abandoned the naturalist paradigm, due to its innate dynamics and due to the influence of non-Western religions/cultures, such as the image-ban of Islam, the image-reluctance of Judaism and the open-ended meaning of Buddhism. As with other visual arts, Western architecture had been based hitherto on the Greco-Christian tradition: tectonic narrative, structural decoration and, in effect, on Aristotle's aesthetics. ${ }^{1}$ Prior to modernism, architectural theories were reflective, like those of Vitruvius, Alberti and, partially, of Semper too. ${ }^{2}$ However, as modernism rejected tradition, prospective theories and ideologies took precedence in architecture.

I argue that this is the moment, when extra-Western cosmologies began to influence western architecture either indirectly, through the medium of non-western art and architecture - Islamic, Buddhist, etc. - or directly, by incorporating eastern religious or mystical elements into western architectural theory and practice. 
This impact occurred in the form of evolution in the nineteenth century and as revolution in the twentieth. In both cases there were two pivotal innovations prompted by non-western influence: the acceptance of the void (emptiness) and the rejection of narrative content on wall surfaces. The acceptance of the void was fostered by the cosmology of Jewish mysticism and Sufism - God as space or an all-encompassing entity - as well as the idea of holy vacancy in Buddhism as the ultimate cosmic reality. The acceptance of the non-discursive surface, the rejection of the anthropomorphic representation of architecture, the face-façade metaphor for example, (as well as the head-capital, backbone-chimney, eyes-windows, mouth-door metaphors) relates to the image ban in Islam, which is actually rooted in Judaism. ${ }^{3}$

Islamic culture developed effective strategies to overcome architecture's discursive character, either by introducing an independent layer of geometric surface decoration over the actual structure (load-bearing walls, pillars), or by carving out the stone to form a geometric 'lace'. This geometrical layer in Islamic architecture fosters meditation on the greatness of the Lord - actually eliminating corporeality and the fear of the idolatry that it may induce - while Judaism on the whole left the visual element out of the system. The non-discursive surface or the surface with open-ended meaning ${ }^{4}$ is also a tool of Zen Buddhist art and architecture. Numerous Zen interiors and gardens bear witness to the strategy of encouraging meditation, closing the visual channels in order to make it possible to "see". Judaism and Jewish mysticism, on the other hand, have been more effective in establishing a cosmology based on space-centeredness and the involvement of time in modern architecture.

I argue that Western acceptance of some elements of eastern cosmologies was essential in the build-up of modern theories in $20^{\text {th }}$ century architecture.

\section{THE INFLUENCE OF ELEMENTS OF ISLAMIC COSMOLOGY}

Nineteenth-century Western acceptance of Islamic architectural tradition was prompted by the need to decorate cast iron, the new structural material. It was Sir Christopher Paxton, who commissioned Robert Owen Jones to decorate the Crystal Palace (1851), in order to make its stark structure aesthetically acceptable to the contemporary public. Jones, author of the influential book The Grammar of Ornament (1856), utilised Islam's visual heritage to meet the needs of the modern architecture of the period. Sufism's insistence on the void, actually space, combined with western rationality (the industrial production of cast iron) represented a 'marriage of convenience', becoming a milestone in the development of modern architecture and one of the first major steps in cultural globalisation. ${ }^{5}$ Soon after that, "oriental style", actually a free mix of mainly Islamic decoration, began its triumphal march through western cities, charted by the architecture of synagogues, buildings of entertainment, and zoos, all of which used modern metal-bearing structures. ${ }^{6}$

Islam and Orientalism, its Western projection, provided the emancipated Jews for the first time with a viable means of achieving a special kind of 'idol-free' or 'idol-proof' expression. Islamic architecture, as an expression of a monotheistic faith other than Christianity and Judaism, offered a strategy for de-materialisation ${ }^{7}$ and de-signification ${ }^{8}$. Synagogue architects did not strive always for actual de-materialisation, but more often settled for the mere impression of it, by covering up the structure with a layer of textile-like decoration. 
This process of virtual de-materialisation aimed at concealing structural material, the tectonic architectural reality. ${ }^{9}$ Islamic architecture may have been the inspiration for Gottfried Semper's ${ }^{10}$ Bekleidungstheorie - one of the basic concepts of nineteenth-century architectural theory - although the role of colours in Greek architecture is usually cited ${ }^{11}$ as his main inspiration. ${ }^{12}$ However, it is hard to believe that Greek architecture, with its painted structural decoration, could have led to the ideas of placing an independent dressing over the structure and of conceiving architecture as textile - Wand and Gewand (wall and textile in German). The analogy of the carpet and the wall is explicitly Islamic. This process of covering up later became one of the preconditions for the separation of the building into its independent dressing on the one hand, and its actual load bearing structure, on the other. This, in its turn, led via art nouveau to architectural modernism proper in the 1920s and 1930s. ${ }^{13}$

In Islamic architecture the primary meaning of a building appears on the surface and not in the solid body of its architecture, in its tectonics and 'structural discourse'. The surface, often abstracted from the building's load bearing-structure, becomes a 'book', on which external (non-architectural, often textual) elements are written: the brick or stone structure is clad with shiny ceramics carrying repetitive ornamentation or calligraphy. In the process, architecture is automatically de-signified. The surface, detached from the internal contents of the architecture (structure, static, etc.), becomes a textual attachment, conveying sacred script or neutral geometrical decoration. The body of the building ceases to emanate the "visible presence of the divine in a work of man", as Hegel and Winkelmann defined the arts, and, therefore, from an Islamic and Judaic point of view, avoids any relationship with idolatry. Moreover, shifting the emphasis from material to space de-idolises architecture further.

On the subject of the significance of space versus corporeality in Islamic cosmology, Seyyed Hossein Nasr writes: "...the positive significance of the void in the Islamic religious consciousness, was thus able to create a space in which the very absence of corporeality led to inwardness and contemplation... The void then plays a positive role in both Islamic art and architecture by making matter transparent and revealing its impermanent nature... Because in Islam the Divinity was never identified with any descent or concrete manifestation or incarnated in a specific form, it has remained always in the Islamic consciousness as absolute and infinite... It appears from the point of view of men living in the domain of corporeality as a reality so transcendent and beyond the material that its presence can be felt in the corporeal world only with the help of the void. The use of the void in Islamic art thus became, along with the use of geometric and other forms of abstract symbolism, the only way to indicate through the means of art and architecture the Unity which is at once everywhere and beyond all things..."14 The architectural product of Islam coincides with the Hebrew Bible's preference for text as opposed to image, although architecture related to Judaism did not follow the Islamic technique until the mid-nineteenth century. The insistence on the void in Islam also coincides with the concept of space and space-time in Judaism.

Referring to Islamic culture, Oleg Grabar emphasises the "rejection of mimetic representation in anything official or formal", which elevates writing to become the main vehicle for signs of belief, power, legitimacy, and any one of the functions for which images were used elsewhere ${ }^{15}$. As a matter of fact, writing and geometrical ornament - actually another type of writing according to Grabar - conquered the surface of buildings. He explains that "geometry is a perfect intermediary, for it attracts not to itself but to other places or to other functions than itself," "16 thus, not directly to 'idolised' contents. However, this type of geometry is far from 
the Greek idea of "geo-metry," measuring the Earth, to establish an underlying meta-system. Grabar continues: "In all cases, the geometry is a passage, at best a magnet, to something else that it does not identify with, but which the culture deems desirable... On the other hand, some geometric designs are an end in themselves, which, endowed or not with identifiable connotative meanings, become their own objects of contemplation. At times, as in the Alhambra, they even acquire signs, poems in this case, indicative of their specificity. At this, relatively rare level, the intermediate geometry becomes the object of emotional or psychic involvement. Within this scheme, geometry is no different from writing. It, too, is a system of arbitrary rules manipulated for culturally significant purpose other than itself and ending up, because of this manipulation, by occasionally producing works of art". ${ }^{17}$ Later this 'book' inscribed on the surface will be abolished, helped on its way by Buddhism and Judaism, creating undecorated, white modernist walls.

\section{THE INFLUENCE OF BUDDHIST COSMOLOGY}

Buddhism's main contribution to modern architecture, like Islam's, lies in its positive view of the void, as absolute nothingness, the sunyata from Mahayama Buddhism. This view easily translates into architectural space, and to space which is not the absence of material - gaps between columns and walls - but a positive entity, a content, a starting point for thought and architectural design.

In Western metaphysics, nothingness is the beginning. In the Bible, Creation begins with overcoming (Überwindung) nothingness; the critical point is when God's idea starts to materialise. The resonance of two words, which are basically of similar literary meaning, vacuum and nirvana (extinguish) illustrates the different attitudes of the West and East towards nothingness. The void (vacuum) in the Greco-Christian world has a negative connotation, echoed in the Latin phrase horror vacui or its Greek counterpart cenophobia (fear of the empty), both applied primarily to the filling in of the entire surface of a space or an artwork with detail. The reason that a void creates horror is that emptiness (the nihilum) negates the raison d'être of Western civilisation, the idea of homo faber, the active creative man and his products (material and intellectual), which he accumulates over the course of time. On the other hand, in nothingness, Buddhism sees purification, enlightenment and redemption.

Buddhism, however, did not deliver the theoretical ground for modernism in terms of space only. In side-lining both surface discourse, the decorated façade, Buddhism touched on the idea of non-cognitive knowledge and communication, i.e. meditation and the meditative experience vis-à-vis Western cognitive experience - verbal, textual and visual.

Meditation or pure experience without subject or object, the zazen of Zen, means that one merges with ones surroundings. As one becomes one with the world, there is no need for any cognitive discourse or logical expression to experience the world. Thus, the pure experience is the rejection of cognitive knowledge, or knowledge gathered by conventional Western differentiation between subject and object, using cognitive processes to decipher the meaning of the architecture. The role of architecture is just the opposite. It does not convey a meaning but helps one to see through closed eyes. In other words architecture becomes a trigger for meditation.

However, while in Muslim architecture the void simply existed as a final cosmic reality (statically, as defined by Seyyed Hossein Nasr), in Buddhist architecture it was paired with 
the idea of indeterminism i.e. passing time, from which the Japanese idea of movement space emerged, and which is closely related to the space-time concept of Jewish Mysticism updated by Einstein's and Minkowski's space-time and 4D space, all resulting in modern architectural space, as we will see later. This is a major cosmological shift in abandoning the Ptolemaic cosmos of static finality.

Indeterminism is one of the most important contributions of Buddhist teachings to modernism. Jewish-Christian concepts of time are determined; mankind is waiting for the Messiah to come. It is not known when, but there is the idea of the end of times at a certain point, which architecture easily translates into a point or a spot towards which the via sacra of the church leads, marked by the altar. Buddhist time does not head towards any end, any firm point, it just flows endlessly.

Buddhism impacted modern architecture mainly indirectly through Buddhist architecture, because Buddhism works primarily not in a cognitive but in an intuitive way, so it is more easily conveyed to the West through pieces of art than philosophically. In this context, the most prominent influence came via Japanese art and architecture as exemplified in the work of Frank Lloyd Wright, Adolf Loos, de Stijl, and later Ludwig Mies van der Rohe, Alvar Aalto, Carlo Scarpa, etc. They took over Japanese spatial principles and some of their ideas of detailing.

\section{THE INFLUENCE OF JUDAIC TEACHINGS AND ALBERT EINSTEIN'S COSMOLOGY}

As we have seen, Buddhism was essential in delivering the space-centred concept of modern architecture. Still, Buddhism's agnosticism and refusal to verbalise ideas, prevented it from creating theories of modern architecture in the West. Instead, Buddhism inspired practical architectural design, leaving Judaism to apply the ideas of the primacy of space and the absence of ornament. Einstein's physics, rooted in Judaic thought ${ }^{18}$, helped Adolf Loos to formulate Raumplan and Siegfried Gidion's Raumzeit. Moreover, the Judaic ban on images encouraged the rejection of ornament in modernism and prompted the introduction of purist white, unadorned façades, as outlined in Adolf Loos' essay Ornament and Crime. ${ }^{19}$

Einstein published "On the Electrodynamics of Moving Bodies" in 1905, connecting time, distance, mass and energy - notions that inspired the most important catchwords of modern architecture. Einstein's preoccupation with the space-time relationship reflects some of the ideas of the Medieval Jewish thinker Maimonides. By 1907, Einstein's former teacher and friend, Hermann Minkovski ${ }^{20}$ realised that the special theory of relativity could be best understood in four dimensional space, now known as "Minkovski spacetime", in which time and space are not separate entities but intermingled in four dimensional space-time. Through his scientific intuition, he created a hypothesis of the unity of space and time, to determine the geometric structure of that space-time unity. Minkovski stated that, in the four-dimensional world, one point has four coordinates: three of which are space coordinates defining the event location, with the fourth coordinate defining the time of the event. This four-dimensional space is called an event space or Minkovski space.

By linking space to time - instead of place (space around something or between) - topos has been successfully eliminated from cosmology and architecture. Similarly, limitation has also lost its significance. Walls no longer limit space; space becomes limitless, infinite, or to use a traditional Hebrew notion ein sof (no end). 
This is one of the most important attributes of God as portrayed in Judaism. Hence, the most basic ideological elements of modernism, placelessness and unlimited space, are closely related to Judaic heritage.

Moreover, Einstein's discovery of the quantum in 1909, creating an understanding of waves and particles together, touched on Jewish tradition. Einstein's suggestion that light possesses a dual nature, i.e. the unification, in one entity, of two opposite concepts of a particle of matter and of a wavy motion, resembles the teachings of Jewish mysticism. Kabbalah uses light as a metaphor for the power of God. It speaks in terms of the Or Ein Sof - the Infinite Light. ${ }^{21}$ One of the principles of faith is that God is omnipotent and may carry opposites. The fact that light possesses a dual nature and can carry an opposite makes it the perfect metaphor for divine energy. In this third stage of the development of light theory it becomes apparent that this unification of two concepts underlines the unity of God within creation. ${ }^{22}$ This new idea became the basis for the new fundamental theory of quantum mechanics from which architectural ideologies profited greatly during the early modern period.

In 1915, Einstein with his theory of general relativity transformed space into time, or 'spatialised' time, and spoke of a 'space-time continuum'. Relativists no longer referred to a 'universal time' and an 'absolute space.' The properties of space-time depend on the speed at which a moving object travels, and at speeds approaching the speed of light, space-time 'contracts' around the moving object. But the time of relativity, like that of classical physics, remains reversible.

These ideas could not remain in the domain of physics in an age when architectural theory yearned for new input and ideas. Adolf Loos was the first, as early as 1912, to translate the idea of a space-centred view into architecture with his notion of Raumplan. It will be the tenet of modernism after World War One. The concept of Raumplan means that the architect is primarily concerned with creating space - not façades, columns, arches, decorations, etc. - and leading or moving people through this space. Space is not just a gap, as between two Greek columns, but becomes a positive 'tangible entity', which is then wrapped up by material. Interestingly, the interior space in Loos' villas is centrifugal, with action shifting to the perimeter of the space, leaving the centre empty, or 'spatial', thus emphasising the emptiness as the most important feature. It is similar to the emptiness in Japanese architecture. Movement in this space is not axial any more - unlike the via sacra in churches or enfilade in palaces, for example - but rather informal and labyrinthine. Sometimes interior space spills over from the perimeter of the building, bulging out from the façade, as in Villa Moller, letting space come to the fore, as an independent entity, which may, or may not, be followed by a load-bearing structure. $^{23}$

In practice, in actual structural terms, Raumplan meant that the regular rhythm of walls and ceilings was abandoned, and space was tailored freely, according to its function. Walls, usually undecorated and white, just served as limiting elements of space. It was not only the width and the depth of space that varied in the plan, but the height too. The load-bearing structure and decoration, when it existed at all, were downgraded in importance with space becoming the critical element. Moreover, the Raumplan was Loos' effort to rethink the traditional 2D planbased configuration of space within a predetermined volume and to extend it to a free 3D disposition with time as the fourth dimension. Loos tried to design each room individually, with the height most appropriate for it. The result was a 3D spatial plan consisting of small, volumetric rooms connected by short staircases, a sort of spatial labyrinth that could be comprehended 
only in time - there was no other way of understanding space other than by moving through it, i.e. involving time in the architectural experience. This was a great historical innovation for modern architecture. It is true that historical architectural spaces also involved time, like Gothic churches, which required walking through the nave and transept in order to reach the apex of spatial experience. However, even without moving, one could quite easily guess the layout of a church just by looking from a vantage point into the nave and aisles. But in order to experience Loos' spaces, one must pass through all corridors and staircases and stationary spaces. Architecture thus becomes a spatial experience, a concept that would be taken up by Le Corbusier's best villas in the 1920s and 1930s, albeit without the variable height.

Loos' space-time concept was still 'slow'. He did not consider incorporating speed into his approach though it was an idea that would subsequently change the constants of space-time. It was the Jewish born modernist, Erich Mendelssohn who went further and increasingly spoke about speed, the $4^{\text {th }}$ dimension of his space. The idea of speed proliferated in the 1910s, with futurism and expressionism using the notion quite frequently. However, Mendelssohn, having personal contact with Einstein, went much further. The equation of matter and energy $\left(E=m^{2}\right)$ had captured his imagination and he used it to explain his concepts in terms of the latent energy of masses and volumes..$^{24} \mathrm{He}$ was also fond of speed, as mentioned, and expressed it both at his Mosse-Haus in Berlin and the Einsteinturm in Potsdam. ${ }^{25}$ The latter became a paradigmatic building that linked state-of-the-art physics with modern architecture.

Finally, after Mendelssohn, it was Siegfried Gidion ${ }^{26}$, the Czech-Jewish-born Swiss art historian, who summarised many of the theoretical achievements of the period to create an ideological base for architectural practice. The most important theoretician of early modern architecture, Gidion emphasised the significance of space-time for modern architecture, largely following Einstein's and Minkowski's ideas. He also found the fourth dimension of Cubist painting in architecture while explaining the corner of the Bauhaus workshop wing by Walter Gropius. ${ }^{27}$

In his book Space, Time, Architecture, in the chapter titled The Termination of the Perspective, Gidion celebrates the departure from the traditional 3D representation used in painting since the Renaissance, and the rejection of the philosophy that the viewer is at the centre and that vanishing points exist. His de-centring of the universe is related to the Einsteinian cosmology. Gidion maintains that the essence of space is not in the optical infinity of the Gardens of Versailles, but in the infinite possibilities of its internal relationships - an almost structuralist idea rooted in Jewish and Eastern (Buddhist) thinking. He maintains that in order to understand space, one must move through it.

Gidion echoes Judaic thought and Einstein's theories when he stresses that space in modern architecture becomes comprehensible only vis-à-vis a moving vantage point and not as the absolutely static unity of Newton's Baroque system. He finds the roots of modern art and architecture in the idea of simultaneity based on Einstein's Electrodynamics of Moving Bodies (1905) and the quoted work of Minkovski on space-time, actually found in the works of Maimonides and in the Kabbalah.

To sum up, early modern architecture was influenced by scientific discoveries, modern art and non-Western religious teachings and cultures, which replaced or supplemented the hitherto dominant Greco-Christian cosmology, which regulated the arts and architecture of the West. Thus, religious cosmology of Islam, Buddhism and Judaism as well as physical cosmology of 
Albert Einstein inspired new thinking on space, the relationship of the building vis-à-vis its environment.

Islamic cosmology, which emphasized the significance of space and void versus corporeality and which banned depiction of humans and introduced abstract geometrical ornament significantly, contributed to space centredness of modernism. Moreover, Islamic architecture concentrated on the surface and not on the solid body of architecture, its tectonics and 'structural discourse'. This surface is often abstracted from the building's load bearing-structure, carrying contents external to architecture in the form of intensely craved stone, airy gypsum mesh or shiny ceramics, carrying repetitive ornamentation or calligraphy, which effectively de-signify architecture.

Buddhism's main contribution to modern architecture, like Islam's, lies in its positive view of the void, as absolute nothingness, the sunyata, which easily translates into architectural space, which is not the absence of material - gaps between columns and walls - but a positive entity, a content, a starting point for thought and architectural design. Meditation or pure experience without subject or object, the zazen of Zen, means that one merges with ones surroundings and there is no need for discoursive surfaces in architecture. The rejection of cognitive knowledge, or information gathered by conventional Western differentiation between subject and object, using senses frees architecture to present contents and promotes it to be just a trigger for non-cognitive communication. Moreover, while the Islamic concept of void is basically static, Buddhism introduced the idea of permanent change and indeterminism which contributed to the concept of movement space in architecture and gardening.

The Judaic concept of space-time, particularly in Einstein's rereading and updating for modern science, contributed to the development of space-centredness and dynamism of modern architecture. Judaism's linking space to time successfully eliminated topos from cosmology, promoting time as the most significant element of cosmology. Moreover, the traditional Hebrew notion of ein sof (no end), one of the most important attributes of the Lord in Judaism, contributed to a revaluation of the traditional concept of infinity prevalent since the Baroque. Walls no longer limit space; space becomes limitless, infinite and dynamic, involving time. Adolf Loos' Raumplan is a direct descendant of this physical concept. Relativity theory stated that space-time depend on the speed at which a moving object travels giving birth to Siegfried Gidion's Raumzeit and to 4D dynamic thinking in architecture, exemplified in the opus of Erich Mendelssohn in the 1920s, which was later taken over by many modernists. 


\section{ILLUSTRATIONS}

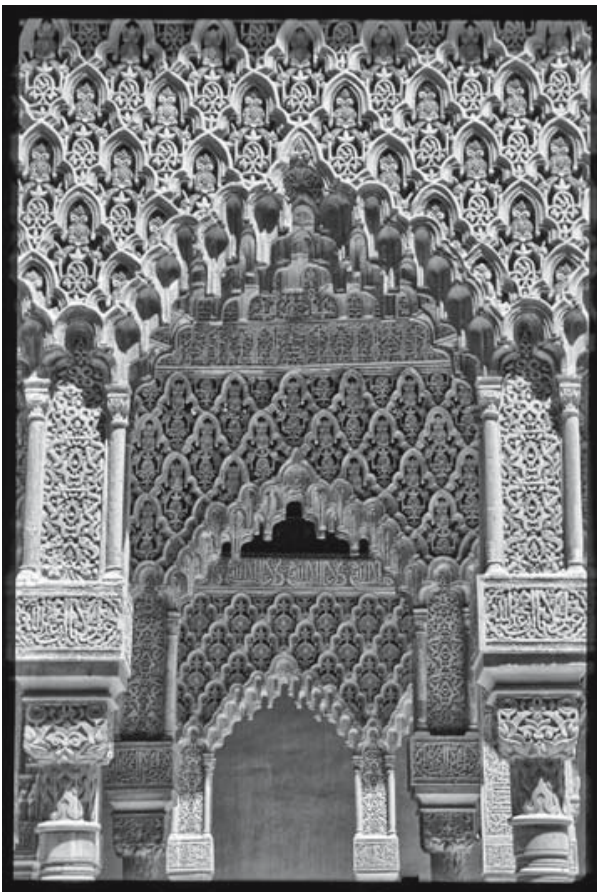

1. Detail from thje Court of the Lions in the Alhambra 1362-1391.

Material is rendered spatial: minimised and looks airy.
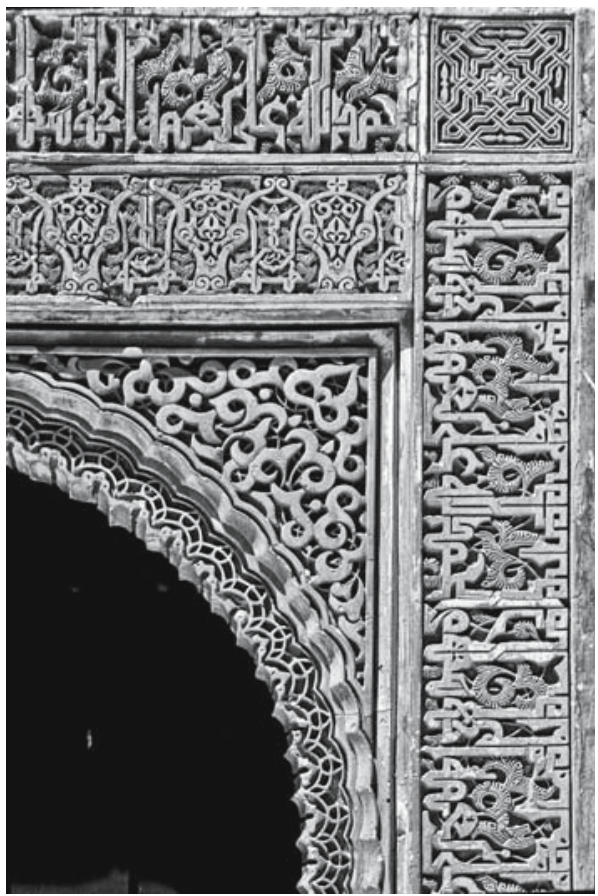

2. Detail from thje Court of the Lions in the Alhambra. The surface emerges as the primary bearer of its content and not the main body of its architecture.

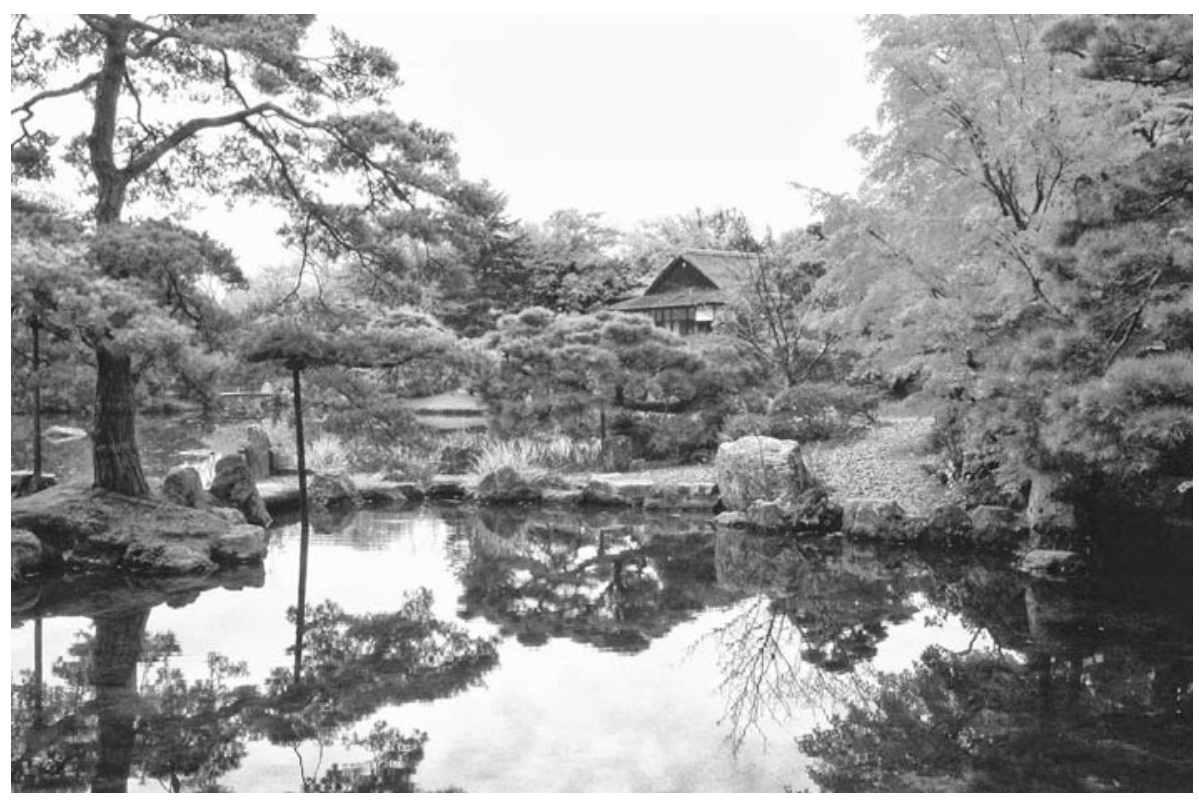

3. The Garden of Villa Katsura, Kyoto, 17th century.

The scrolling garden exemplifies permanent change, indeterminism. 


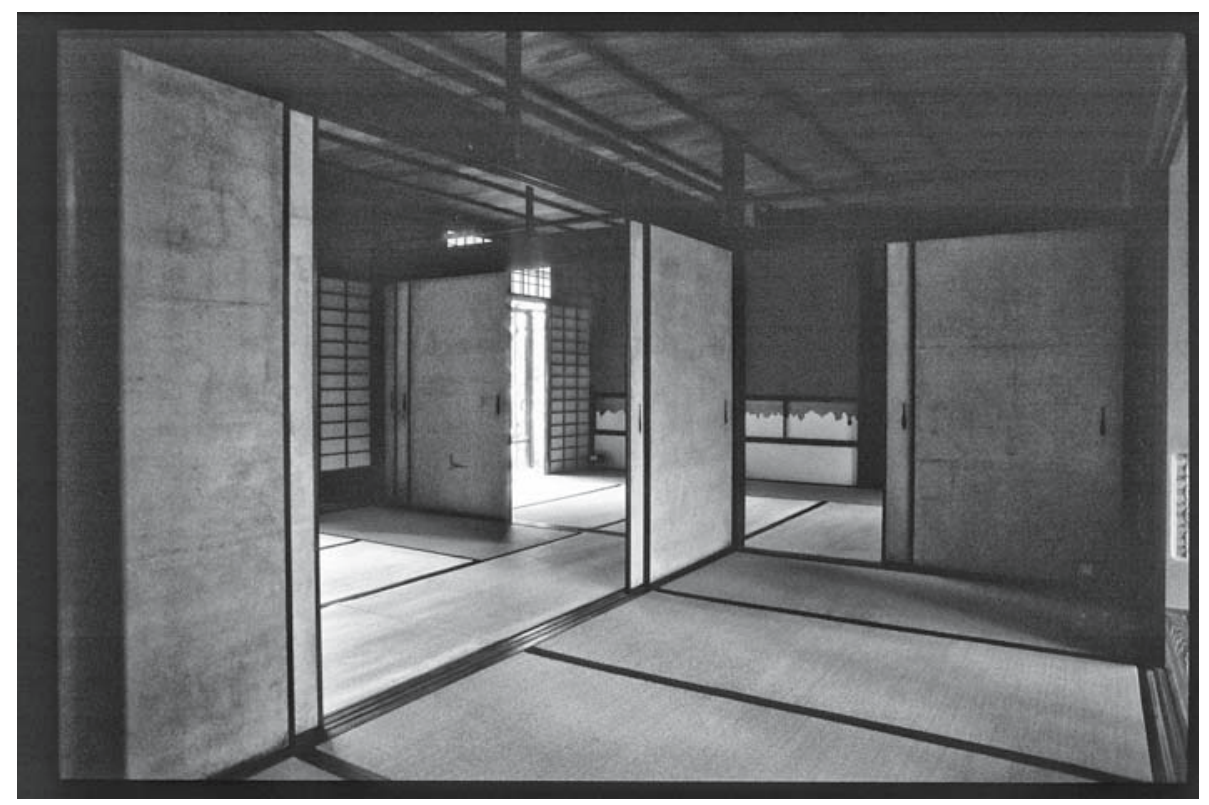

4. Interior of the Shokin-tei in Katsura Rykiu, Kioto, 17th centuri. Space flows freely among movable panels without any decoration.

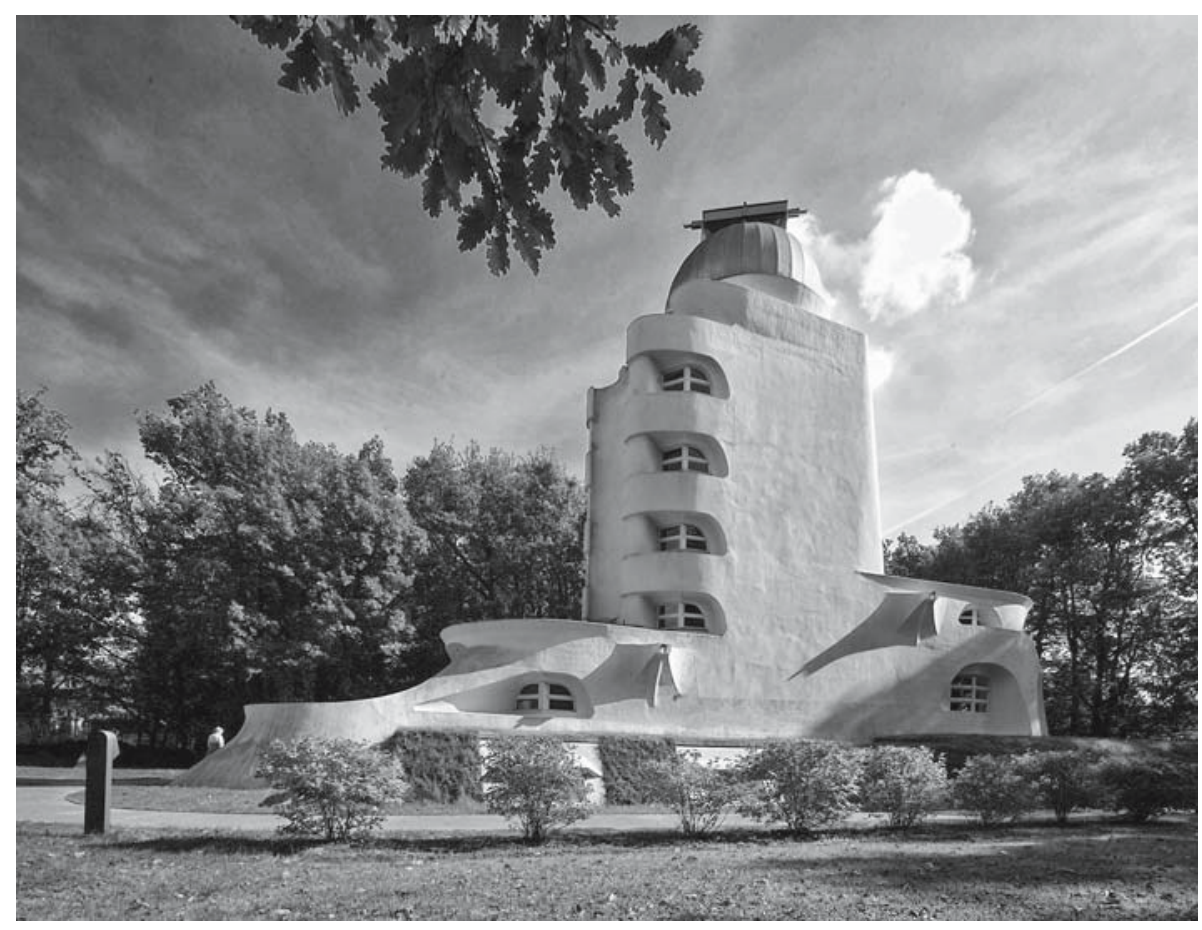

5. Erich Mendelssohn, Einsteinturn, built from 1919 to 1921.

The streamlined, organic from corresponds to elements of Einstein's teaching. 


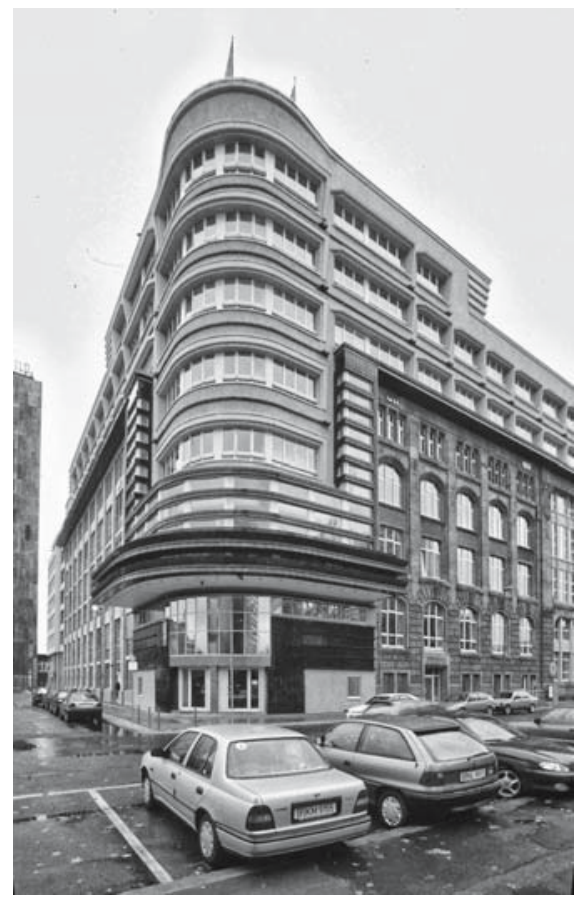

6. Erich Mendelssohn, Mosse-Haus, Berlin, 1921-23. The architect sproke of speed, energy and different experiences of the building depending on whether the beholder walked or drove a car.

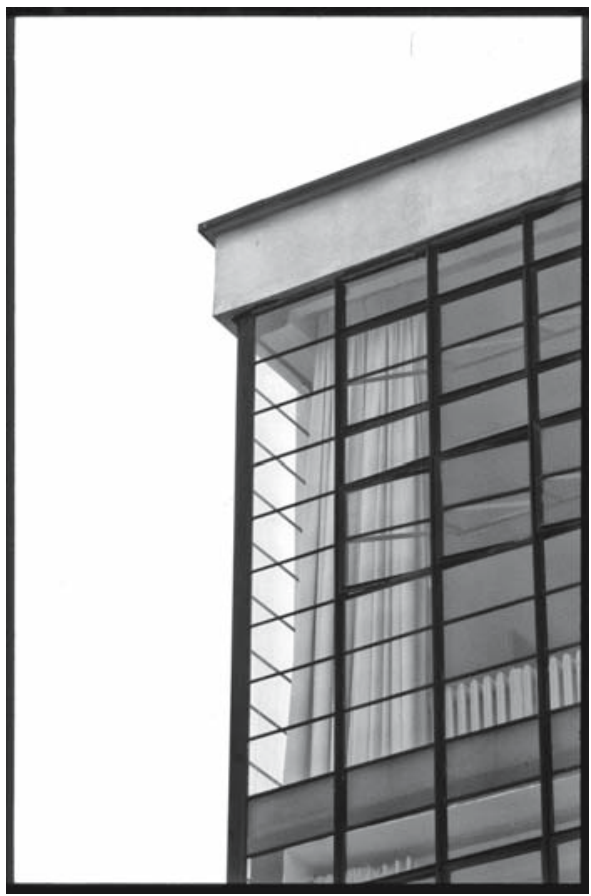

7. Walter Gropius, Detail of the Bauhaus's workshop wing, Dessau, 1925-26. Siegfried Gidion likened the experience of the corner of this building to a cubist painting, with the simultaneous view of an object from different sides.

\section{REFERENCES AND NOTES}

[1] In his Metaphysics, Aristotle writes that "the primary features of beauty are taxis, symmetria and horismmenon, and that they can be expressed mathematically". Taxis meant order, which also implied hierarchy. Symmetria derives from syn, meaning common, and metreo, meaning measurement; symmetria refers to systematic division of a piece of art into equal measures or quantities and symmetry. Horismmenon, meaning limit, was an element that mostly determined architectural space, and was only conceivable as limited. All these elements are in fact geometrical, describing cosmology.

[2] Semper in his Bekleidungstheorie was the first to usher non-Western ideas which can be related to Islamic tradition.

[3] The text of the Second Commandment made Judaism reluctant to tackle the issue of the visual element, as it is less strict than Islam, but also less willing to address the problem of representation, actually non-representation.

[4] for instance wall painting with some empty patches, faint lines, which can be interpreted in several ways.

[5] There have been earlier 'cultural borrowings,' like Johann Fischer von Erlach's use of the minaret in his Karlskirche in Vienna, or John Nash's Royal Pavilion in Brighton that used Indian architectural elements, but they did not create a new paradigm.

[6] Some Orthodox churches in the Habsburg Empire, built in a Catholic environment, also used oriental elements in order to differentiate them from the mainstream western architecture.

[7] I use the term de-materialisation to denote the gradual process of the reduction of building material in the evolution of historic styles. This process can be extrapolated to the history of architecture as a whole, Western and Far Eastern alike. Not only did the quantity of material diminish from the era of the Egyptian pyramids down to the time of Ludwig Mies van der Rohe's Friedrichstrasse project in Berlin in the 1920s, but also its prominence and expressive power. I suggest that this is not only the result of technical, but also of spiritual progress, the shift from the touchable sacred entity to the abstract, in accordance with the evolution of civilisations. This could be related to the development of religious thought from animism and polytheism to monotheism and atheism (in its Western or Zen Buddhist version, for instance). 
[8] Parallel with the process of de-materialisation evolves de-signification, whereby architecture gradually loses its power to represent external and internal contents, which produces more simulacra with more and more remote references, until the extreme concept of non-referentiality is reached. The joint effect of de-materialisation and de-signification can be described as the de-idolisation of architecture, a process, which distances architecture from the idol, or the material manifestation of the sacred.

[9] Contemporary critics stressed the 'restless spirit' of oriental style, as opposed to solid Western tectonics and the concept of eidos which lies behind it. See: Rosenthal, „In welchem Style sollen wir bauen?“ In: Zeitschrift für praktische Baukunst, (4/1844): 23-27. The author of the paper adds that this style lacks any Christian element and architectural character, being merely decoration and play.

[10] Gottfried Semper (1803, Hamburg - 1879, Rome), the most prominent German architect of the second half of the 19th century, created the Dresden synagogue (1838-40), a turning-point in this genre. His Der Stil in den technischen und tektonischen Künsten, 1860-63 ("Style in the Technical and Tectonic Arts") is the most profound theoretical treatise of the century. It advocates a rational interpretation of techniques as a source of style, and recommends the use of colour in decorative arts and architecture, which with his Bekleidungstheorie (theory of cladding), served as the theoretical justification for the Oriental style.

[11] In 1834 Semper published Vorläufigen Bemerkungen über bemalte Architektur und Plastik bei den Alten " in which he analysed the question of polychromy in antiquity with some references to medieval and Renaissance architecture. Following many other scholars, Hanno-Walter Kruft concludes that polychromy led Semper to the idea of the 'theory of cladding'. („Die Polychromie wird für ihn zum Ausgangspunkt seiner später entwickelten Bekleidungstheorie.“) See: Hanno-Walter Kruft, Geschichte der Architekturtheorie, (Munich, 1985) 356.

[12] The proof of this is the interior of his synagogue in Dresden, where oriental style was only used in the interior. Later, mainly after the 1848 revolutions, codification in architecture slackened and opened the way to new languages in Central Europe. The first large-scale 'Oriental style' synagogues first appeared in the $1850 \mathrm{~s}$.

[13] This split was far from the original intention of Islamic sacred architecture.

[14] See: Nasr, Islamic Art and Spirituality, 190.

[15] Oleg Grabar: The Mediation of Ornament, (Boston, 1992), 63.

[16] Grabar, The Mediation of Ornament, 151.

[17] Grabar, The Mediation of Ornament, 152.

[18] Albert Einstein originated from a German Jewish family and he was familiar with Judaic thought and interpreted it similarly to Baruch Spinoza. Einstein was sympathetic towards Buddhism, but his insistence on God is explicitly Jewish. See: Rudolf Klein: Judaism, Einstein and Modern Architecture, in Prostor, 2[44] 20[2012] 220-235.

[19] Loos, a gentile surrounded by Jewish intellectuals, explicitly mentions the 'white walls of Zion'.

[20] Hermann Minkovski (1864-1909), mathematician, born into a Lithuanian Jewish family, but he was not involved spiritually in Judaism.

[21] Einstein's quantum theory for which he obtained the Nobel Prize is often related to Jewish mysticism. The Kabbalah sees the universe as little bits of dark matter which are surrounded and held together by a light called ein sof. Quantum theory sees the universe as little particles with positive and negative and neutral charge which are surrounded by and held together by 4 forces: gravity, electromagnetism, strong, and weak.

[22] See for Judaic roots of Einstein: Steven Gimbel, Einstein's Jewish Science: Physics at the Intersection of Politics and Religion, The Johns Hopkins University Press, Baltimore, 2012

[23] As a matter of fact, space has always played an important role in architecture, particularly in explicitly spiritual periods such as the Gothic and the Baroque. Even then, space was an integral part of planning, with structural elements carefully drawn and designed. However, space was treated as something between objects and structures and not as an independent entity.

[24] Mendelssohn's wife's friend, Erwin Finlay-Freundlich was one of the first to learn about and support Einstein's endeavours. He planned to measure the bending of light during a solar eclipse, and published the first book on relativity in 1916.

[25] In the 1920s and 1930s, architectural theoreticians considered Mendelssohn's early opus to be expressionistic, which may be true, but his ideological impact was undeniable and necessary for the further course of architectural modernism.

[26] Siegfried Gidion (Prague, 14 April 1888 - 10 April 1968 in Zürich, sometimes misspelt Siegfried Giedion) was a pupil of Heinrich Wölfflin, but soon adopted modern thinking in cosmology and the physics of Einstein. As the first secretary-general of the Congrès International d'Architecture Moderne he was extremely influential in modernism's evolution and spread.

[27] Although influential, this connection between the Bauhaus' corner and cubist paintings of Braque and Picasso is a bit problematic, and it reflects Gidion's view of architecture from an art historian's perspective. 